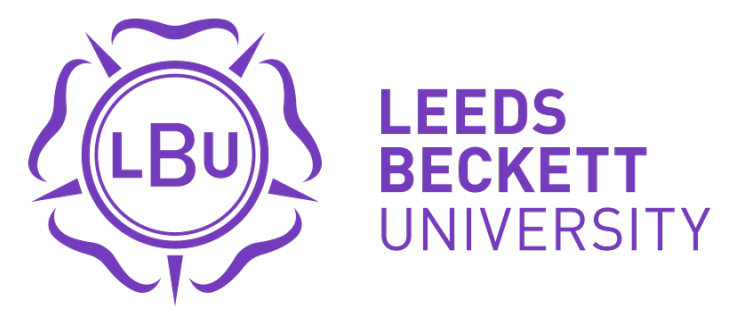

Citation:

Swann, C and Piggott, D and Schweickle, M and Vella, S (2018) A Review of Scientific Progress in Flow in Sport and Exercise: Normal Science, Crisis, and a Progressive Shift. Journal of Applied Sport Psychology, 30 (3). pp. 249-271. ISSN 1041-3200 DOI: https://doi.org/10.1080/10413200.2018.1443525

Link to Leeds Beckett Repository record:

https://eprints.leedsbeckett.ac.uk/id/eprint/4768/

Document Version:

Article (Accepted Version)

This is an Accepted Manuscript of an article published by Taylor \& Francis in Journal of Applied Sport Psychology on 23 February 2018, available online: http://www.tandfonline.com/10.1080/10413200.2018.1443525

The aim of the Leeds Beckett Repository is to provide open access to our research, as required by funder policies and permitted by publishers and copyright law.

The Leeds Beckett repository holds a wide range of publications, each of which has been checked for copyright and the relevant embargo period has been applied by the Research Services team.

We operate on a standard take-down policy. If you are the author or publisher of an output and you would like it removed from the repository, please contact us and we will investigate on a case-by-case basis.

Each thesis in the repository has been cleared where necessary by the author for third party copyright. If you would like a thesis to be removed from the repository or believe there is an issue with copyright, please contact us on openaccess@leedsbeckett.ac.uk and we will investigate on a case-by-case basis. 
Publisher: Routledge

Journal: Journal of Applied Sport Psychology

DOI: https://doi.org/10.1080/10413200.2018.1443525

A Review of Scientific Progress in Flow in Sport and Exercise: Normal Science, Crisis, and a

\section{Progressive Shift}

Christian Swann ${ }^{1,2^{*}}$, David Piggott ${ }^{3}$, Matthew Schweickle ${ }^{1}$ \& Stewant A. Vella ${ }^{1}$

${ }^{1}$ University of Wollongong, New South Wales, Australia

${ }^{2}$ Southern Cross University, New South Wales. Australia

${ }^{3}$ Leeds Beckett University, Leeds, UK

Submission date: $1^{\text {st }}$ November, 2017

Resubmission date: $15^{\text {th }}$ February, 2018

*Correspondence concerning this article should be addressed to Christian Swann, School of Psychology, University of Wollongang, Wo!longong, New South Wales 2522, Australia. Email:

cswann@uow edu au, Telephone: (+61) 242214526.

Abstract

Flow is highly relevant and desirable in sport and exercise. Drawing on ideas from iconic philosophers of science - Thomas Kuhn, Karl Popper and Imre Lakatos - we argue that research in this field has followed a pattern of 'normal science.' With a series of accumulating criticisms and 'anomalies', we propose flow research is approaching a 'crisis point'. We highlight problems with research based on the traditional nine-dimensions conceptualization of flow. Then, drawing on the 
work of Popper and Lakatos, we offer theoretical and methodological suggestions for developing a more progressive and practically useful theory for researchers and practitioners.

\section{Keywords}

Clutch, enjoyment, optimal experience, performance, philosophy of science. 
Flow is commonly defined as an intrinsically rewarding, harmonious psychological state involving intense focus and absorption in a specific activity, with a sense of everything coming together or clicking into place, even in challenging situations (Csikszentmihalyi, 2002). Flow has been associated with exceptional performance (Jackson, Thomas, Marsh \& Smethurst, 2001), as well as factors underlying long-term participation in sport and exercise, including: engagement (Hodge, Lonsdale \& Jackson, 2009); enjoyment (Csikszentmihalyi, 2002); motivation (Valenzuela, Codina \& Pestana, 2017); and wellbeing (Schüler, Brandstätter \& Sheldon, 2013). Indeed, flow has increasing potential in exercise and physical activity promotion given the importance of positive experiences for long-term participation (Rhodes \& Kates, 2015). As such, flow is highly relevant in snort and exercise $^{1}$, and has been studied in this domain since the early 1990s (e.g. Jackson, 1992, Kimiecik \& Stein, 1992). Since then, there have been a number of highly cited and influential studies (e.g., Jackson, 1995, 1996), validated questionnaires (e.g., Jackson \& Elılund, 2002, 2004), a systematic review (Swann, Keegan, Piggott \& Crust, 2012), book chapters (e.g., Jackson \& Kimiecik, 2008), and books (Csikszentmihalyi, Latter \& Weinkauff Duranse, 2017; Jackson \& Csikzentmihalyi, 1999). Despite such progress, a number of criticisms and important questions have also been raised about Csikszentmihalyi's conceptualization ff flow and the state of research on this concept (e.g., Voelkl \& Ellis, 1998; Kowal \& Fortier, 1999; Hoffman \& Novak, 2009; Hassmén, Keegan \& Piggott, 2016). Further, new and emerging insights stemming from recent research in sport and exercise (see Swann, Crust \& Vella, 2017) have raised questions over fundamental assumptions about flow, and even the validity of widely use d measures of flow (Jackman, Crust \& Swann, 2017). In turn, there are issues in the application of $/ 10 \mathrm{w}$, in terms of the extent to which athletes, coaches, and practitioners can draw upon the conceptualization of flow to reliably induce these experiences in training and competition.

In light of recent critique (e.g., Hassmén et al., 2016), and suggestions that "research on flow states in sport is plagued by a variety of conceptual and methodological problems" (Moran \& Toner,

\footnotetext{
${ }^{1}$ Other positive psychological states such as peak performance (e.g., Harmison, 2011) and peak experience (see Jackson \& Kimiecik, 2008) have also been studied in sport and exercise; however, flow is the most developed (e.g., with validated questionnaires) and widely studied of these concepts, and therefore the focus of this article.
} 
2017, p.193), it is timely to 'pause and reflect' on the state of flow research in sport and exercise. In order to review and evaluate the state of research on flow, and outline a more progressive program of research and practice, we follow the example of Hassmén et al. (2016) in drawing on the sociohistorical and philosophical ideas of Thomas Kuhn, Karl Popper, and Imre Lakatos. Specifically, we identify problematic, or degenerative, trends in research on flow in sport and exercise; and offer theoretical and methodological suggestions for developing a more progressive and practically usefuí theory for researchers, coaches, practitioners, athletes, and exercisers.

\section{Paradigm Shifts and Scientific Revolutions}

Defining 'progress' in science depends on the philosophical lens througit which you choose to look. Arguably the two most influential contrasting perspectives cn this subject are those of Thomas Kuhn and Karl Popper (see Robergs, 2017 for an excellent sritique in exercise physiology). Although they had different disciplinary interests and goals - Kunn was a historian interested in what scientists do, whereas Popper was a philosopher trying to find ingical rules for what they should do - both have had a significant impact on the way in which we understand the aims and practice of scientific research.

Kuhn's (1996) highly juflutential work, The Structure of Scientific Revolutions, used examples from chemistry, physics and astronomy to describe how scientists typically proceed when conducting research. According to Kuhn, science is a social activity conducted in what he called 'paradigms' (e.g., the values, the ories, concepts, exemplars, methods, tools, language) which provide the "rules of the game' (Kowbottom, 2011), governing scientific behavior. Since scientists are socialized into paradigms, which are implicit and socially constructed, scientific activity in a paradigm is a rather dogmatic and prosaic affair. Indeed, Kuhn gave the label 'normal science' to this unreflective puzzlesilving activity wherein scientists busy themselves with the gradual extension and deepening of the paradigm. Nevertheless, as normal science proceeds, 'anomalies' (i.e., results that do not fit with the predictions of the paradigm) begin to accumulate and, at some point, are considered to constitute a 
'crisis' in the community, sparking a short but intense period of revolution (hence the title of the book).

Science, for Kuhn, is therefore characterized by long periods of paradigm-extending normal science, punctuated by brief, rare (and seemingly irrational) revolutions in which the leaders of a community jump to a new paradigm, taking the rest of the community with them (Pires, 2013). Progress, in this view, has a twofold character. In normal science, progress is a function of the speed or rate of puzzle-solving, facilitated by deep agreement between peers and the development of new, more precise measurement tools (Kuhn, 1996). During revolutionary periods, however, where two or more paradigms come into conflict, progress is defined against criteria from within the paradigm, hence all discussions of progress descend into relativism (Fuller, 2006). In Kahn's view, there are no supra-paradigmatic rules or principles one could use to assess the relative mierits of one paradigm over another.

Karl Popper, by contrast, developed a theory of the logic of scientific progress based on the dual convictions of realism and fallibilism. For Popper (1994), scientific theories aspire to truth (realism) and make testable predictions about the world (i.e., they are falsifiable). Testable theories also lend themselves to criticisnn. and thesries that have undergone harsher tests (i.e., that are better 'corroborated') are preferied as they are likely to be closer to the truth than untested theories. Science therefore proceeds in a contintous process of 'conjecture and refutation' where bold theories are proposed and either oyerthrown in light of criticism, or maintained tentatively (fallibilism) until harsher tesis can be developed (Magee, 1973).

When confronted with Kuhn's ideas about science, Popper recoiled (Popper, 1970) and, whilst he reluctantly admitted that scientists may dogmatically defend their paradigms, he argued that sizch activity was 'pseudoscientific' and would actively stifle progress (i.e., progress towards better, more truth-like, theories). Popper's normative theory of science - what he came to call 'critical rationalism' - is often presented as a more rational and constructive alternative to Kuhn's relativist and conservative vision (Miller, 1994). Critical rationalism is presented both as an attitude, and a 
method. As an institutional attitude it can be summed up in the phrase: "I may be wrong and you may be right, and by an effort, we may get nearer to the truth" (Popper, 1994, p. xii). As a method, it can be expressed as a four phase process: (i) define a problem situation; (ii) offer a tentative solution; (iii) submit the theory to criticism and eliminate errors; and (iv) define the new problem situation (Popper, 1981). Progress, under a Popperian definition, is therefore characterized by an increase in empirica! content of theories (i.e., they predict more novel facts, hence are testable) and the subsequent increase in the degree of corroboration of theories (i.e., we should prefer theories that have survived harsher tests; Popper, 1959).

To summarize, we find Kuhn's ideas useful insofar as they help us identify 'imational' paradigmatic behavior on the part of researchers, and/or provide a critical sociological analysis of possible behavior (cf. Hassmén et al., 2016). Popper's critical ratrenalism then provides a normative framework that provides clear and unambiguous guidance on to achieve scientific progress. This literature therefore forms a basis for evaluating the state of research on flow in sport and exercise. Specifically, this article examines the state of the 'paradign' in flow research. First, we suggest that normal science has characterized much of the period since Csikszentmihalyi's initial 'burst of scientific discovery' in conceptualizing flow by tracing the development of this concept within sport and exercise. Second, we exanine à series of criticisms and/or 'anomalies' which have been accumulating in flow esearch. Thi d, we argue that flow research in sport and exercise has reached, or is approaching, a mornent of 'crisis'. Finally, we offer ideas to inform a shift towards new, emerging lines of thought, and draw on a Popperian notion of progress to explore opportunities for developing theories with greater predictive value and practical utility.

\section{Normal Science and the Flow Paradigm in Sport and Exercise}

Csikszentmihalyi's $(1975,2002)$ conceptualization of flow is purported to apply universally (i.e., in the same way across all domains and cultures). Indeed, it is claimed that "remarkable consistency has been found in the described flow experiences of individuals across diverse settings" (Jackson \& Eklund, 2004, p.3) and that "the original account of flow has proven remarkably robust" 
(Nakamura \& Csikszentmihalyi, 2002, p.90). In sport and exercise, flow is commonly understood in terms of nine dimensions (e.g., Jackson \& Csikszentmihalyi, 1999). Three of these dimensions are proposed to be the conditions necessary for flow to occur (Nakamura \& Csikszentmihalyi, 2002): (i) challenge-skill balance, in which individuals perceive a balance between the challenge of the situation and their skills; (ii) clear goals for the individual to strive towards; and (iii) unambiguous feedback that allows the person to know whether they are progressing towards their goals, or how to adjust in order to do so. The remaining six dimensions are suggested to describe the characteristics of the liow experience (Nakamura \& Csikszentmihalyi, 2002): (iv) action-awareness merging (whereby deep involvement leads to automaticity and spontaneity); (v) concentration on the task at hard with no extraneous or distracting thoughts; (vi) sense of control over the performance or gutcome of the activity; (vii) loss of self-consciousness (i.e., decreased awareness of the self and social evaluation); (viii) transformation of time (i.e., time becomes either speeds up, slows down, or becomes irrelevant); and (ix) autotelic experience ${ }^{2}$ (i.e., flow is described as rewarding and enjoyable).

Jackson's $(1992,1995,1996)$ originat studies were the first to empirically examine how well Csikszentmihalyi's conceptualization applied to sport and exercise. For example, a classic study (Jackson, 1996, p.77) in this field employed interviews with elite athletes from a range of sports to examine "how do athletes' experiences of flow compare with the theoretical descriptions of flow put forward by Csikszentriikalyi (1990)?" Following inductive analysis to generate initial codes, Jackson employed a pricri coding or "deductive analysis in order to examine the fit of Csikszentmihalyi's (1990) model of fiou to the athletes' descriptions" (1996, p.79). This early study presented an indepth perspective of the correspondence between Csikszentmihalyi's dimensions and athletes' descriptions of their flow experience.

\footnotetext{
${ }^{2}$ In some instances - usually outside of sport and exercise - autotelic experience is not seen as a separate or additional dimension but rather a description of the flow experience generally (e.g., Engeser \& Rheinberg, 2008). In sport and exercise, however, the trend has been to present it as one of the nine dimensions (including in Csikszentmihalyi's work; e.g., Csikszentmihalyi et al., 2017).
} 
Importantly, that early work formed the basis of the subsequently developed Flow State Scale (Jackson \& Marsh, 1996), later revised as the Flow State Scale-2 and Dispositional Flow Scale-2 (Jackson \& Eklund, 2002, 2004). Jackson and Eklund (2004) suggested that: "these scales were theoretically grounded in Csikszentmihalyi's (1990) nine dimensional conceptualizations of flow" (p.7); and that "items were developed from the nine dimensions of flow described by Csikszentmihalyi (1990)" (p.26); and "qualitative research examining the flow construct (e.g., Jackson, 1992, 1995, 1996) was drawn upon for the phrasing of items" (p.26). The resultaiti questionnaires have been used widely in sport (e.g., Koehn, Morris \& Watt, 2013), exercise (e.g., Karageorghis, Jones \& Stuart, 2008), and beyond (e.g., music; Wrigley \& Exmmerson, 2013), and have arguably become the primary means of assessing flow in sport and exercise. Therefore, most research in sport and exercise is based on Csikszentmihalyi’s nine dimensions, thro lgh Jackson's early work (e.g., 1996) and subsequent development of the Flow Scales (e.g., Jackson \& Eklund, 2004).

\section{Flow and Normal Science}

From a Kuhnian perspective it might bo considered as a strength that the original conception of flow has been studied across many domains and with thousands of participants. Further, it could also be argued that 'normal science (Kubn. 1996) has been established. In normal science, a core framework (e.g., a set of theories, everiplars, concepts and methodological tools) is implicitly accepted (but not questioned) by researchers within a paradigm, who engage in self-referential "puzzle-solving" activity (Kuhn, 1996). That is, normal science proceeds by extending knowledge of the paradigm (e.g. by observing and experimenting), in accordance with the accepted framework, without challenging or questioning the underlying assumptions of that framework (Kuhn, 1996). There is evidence of 'normal science' in sport and exercise, for example, in qualitative studies that have often used a priori or deductive coding of data into the nine (pre-existing) flow dimensions (e.g., Sugiyama \& Inomata, 2005; Bernier et al., 2009). This approach was used in Jackson's (1996) original qualitative exploration of the flow experience in athletes, whereby Csikszentmihalyi's dimensions were essentially accepted (a priori) as being true. Importantly, that data informed the development of the Flow Scale questionnaires (Jackson \& Marsh, 1996) and their subsequent 
revisions (Jackson \& Eklund, 2002, 2004), which were also based explicitly on Csikszentmihalyi's nine dimensions. Given that the Flow Scales have ostensibly become the primary means of measuring flow in sport and exercise, this implicit acceptance of Csikszentmihalyi's dimensions means that little opportunity has existed for the conceptualization of flow to be anything other than 'supported' or verified in this field.

In turn, the "remarkable consistency" (Jackson \& Eklund, 2004, p.3) and "remarkably robust (Nakamura \& Csikszentmihalyi, 2002, p.90) account of flow identified by researchers is perhaps to be expected. While these early conceptualizations may have played a pivotal role in cieveloping new ideas and directions for sport and exercise research in the early 1990s, continued use of this approach may now be inhibiting scientific progress (Popper, 1959). Current research ir this vein may prevent the emergence of new ideas and insights by reinforcing the accepted flow paradigm without progressing or evolving our understanding of flow. Given the importance of this issue, we will revisit and elaborate on this point in the conclusion.

\section{Criticisms and Anomalies' in Flow Research}

The way in which criticisms are Gealt with in scientific communities may tell us something about the state of the paradign Initialiy, during periods of normal science, criticisms are disregarded (e.g., as 'anomalies') because they do not 'fit' with the underlying theory (Kuhn, 1996; Pires, 2013). These criticisms andior anomakies gradually accumulate until a 'crisis point' is reached and they can no longer be ignored (Kuhn, 1996; Pires, 2013). This section outlines a series of criticisms and/or anomalies in the cyirrent flow conceptualization that we argue have largely been overlooked, ignored, sor dis regardied to date.

\section{How is Flow Experienced?}

Csikszentmihalyi's initial conceptualization of flow (1975) was informed by phenomenological epistemology, which emphasized description of participants' experience (see Csikszentmihalyi, 2000, pp. xiii-xvii). As a result, the initial conceptualization focused largely on 
description rather than theorizing and explanation and, indeed, Csikszentmihalyi (1992) later discussed hesitation about developing a 'mechanistic' explanation of flow:

I guess I have always worried about "breaking the spirit" of flow by defining it too soon and too precisely. At the same time, I've often wondered whether this reluctance to operationalize was not a form of cowardice, a way to avoid exposing the theory to testing and to potential falsification (p.183).

While the resulting descriptive conceptualization of flow has been studied extensively across many areas of research, it has also received criticism. For example, Hoffman and Novak (2009), p.26) argued that: "It is an understatement to suggest that there is some lack of consistency ir operational definitions of flow used by different researchers," while Kowal and Fortier (1999) have also critiqued the "ambiguity concerning individual characteristics of flow" (n.365). The following sections outline a number of issues in the conceptualization of flow in port and exercise.

Imprecise definition of flow dimensions Under critical examination, some terminology used within Csikszentmihalyi's flow conceptualizatien is imprecise and open to interpretation (cf. Swann, Crust, Keegan, Piggott \& Hernmings, 2015). As one example, the type of goal necessary in the clear goals dimension is unclear. There are many different types of goals (e.g., process, performance, outcome - Hardy, Iones \& Gould, 1996; specific, 'do your best' - Locke \& Latham, 2013; emergent goals - Csikszentmihalyi, 1978) but it is not stated whether these are all relevant for flow, and if se, whether they are all equally relevant. An experimental study (Schweickle, Groves, Vella, \& Swann, 2017) found that goal types significantly influenced subjective experience (i.e., flow and clutch states, as discussed below) during a cognitive task, suggesting that clarification of the goal types recessary for flow is highly important. It may previously have been the case that flow di:mensions were defined broadly to maintain relevance across a broad number of domains (e.g., the various activities included in Csikszentmihalyi's initial study in 1975). The broad, and arguably imprecise, definition of these dimensions in sport and exercise is, however, problematic for researchers, practitioners, and athletes/exercisers wishing to apply them. For example, broad 
definitions are more difficult to test or attempt to falsify; more easily allow for the suggestion that flow is experienced in the same way 'universally' (Csikszentmihalyi, 2002); and may ultimately lead to imprecise understanding of flow (e.g., by encompassing almost any aspect of positive experiences).

Overlapping and missing constructs. There is also lack of clarity surrounding the conceptualization of flow in terms of coherence with other constructs in sport and exercise psychology. For example, Jackson and Csikszentmihalyi's (1999) book, based largely on Jackson's (1992, 1995, 1996) earlier empirical work, refers to confidence under three different camensions. challenge-skill balance, clear goals, and sense of control. This issue poses problernatic overlaps, for example, when qualitative researchers seek to code data on confidence duing flow. Other overlaps are also apparent in flow dimensions. For example, loss of self-conscioushess. action-awareness merging, and concentration on the task at hand have all been characterized in terms of feeling 'at one' with the activity (Jackson \& Csikszentmihalyi, 1999). Furthermore, the absence of critical, extraneous, and/or negative thoughts is referred to in concentration on the task at hand, loss of selfconsciousness, and sense of control (Jackson \& Csikszent tnihalyi, 1999). In addition to extensive overlaps within the conceptualization of flow, cere constructs are often reported during flow (e.g., arousal, motivation, confidence) which are not explicitly outlined within the nine dimensions (Swann et al., 2012). Finally, Csikszen mihalyi $s(1975,2002)$ work refers to perceptions relating to the body, and some athletes have røported "brdily sensations" (e.g., Chavez, 2008; Jackman, Fitzpatrick, Lane \& Swann, 2017) dufirg flow. This component is not currently represented in the nine-dimensions conceptualization and ray be specific to sport and exercise (e.g., compared to writing, which does not require vigorots use of the body). As such, the nine-dimensions framework: (i) is missing core aspects of the flow experience, and (ii) includes overlaps in its conceptualization of other experiential characteristics. Together, these issues could be leading to incomplete and/or ambiguous description and understanding of the experience of flow.

Low support for certain dimensions. Another issue in flow research is that certain dimensions have received low empirical support compared to others. For example, in a systematic review of flow in elite sport, Swann et al. (2012) reported that less than $30 \%$ of athletes in the 
included qualitative studies reported the dimensions loss of self-consciousness and transformation of time. In early work in this field, Jackson (1992) found that loss of self-consciousness was not strongly endorsed by a majority of figure skaters in her sample. She suggested they may have misunderstood the concept, and that low support for this dimension "perhaps reflected the ambiguity surrounding what self-consciousness entails" (1992, p.170). In later work, for example in the validation of the Flow State Scale-2, the dimension time transformation exhibited only modest relationships with the other subscales (see Jackson \& Eklund, 2004, pp. 48-51). The low support found for these dinensions in sport and exercise is typically overlooked. For example, subscales for all nine dimensiens are included when the FSS-2 is used in quantitative studies. This issue raises fundamental questions over the flow framework, such as: whether flow should continue to be conceptualized as, nine dimensions; whether dimensions with low support require revision; and how data basec on the flow framework (e.g., the Flow Scale questionnaires) should be interpreted (see Ioliowing section).

\section{How many dimensions are necessary to constituce a low experience? Hassmén et al} (2016) have highlighted that "there is not even agreement about how many of the 'dimensions' need to be present before a flow state can be classified" (p.8). For example, there are suggestions that "experiencing flow means that all components...have to be present" (Engeser, 2012, p.25); and, alternatively, that "some cornponents. .aie not always part of flow experiences" (Schiefele, 2013, p.529). Empirically, 93\% of Jackson's (1996) sample reported themes which fit into five or more of the nine flow dimensions; while Sugiyama and Inomata (2005) reported that an average of 5.8 of the nine dimerisions applied to their athletes' experiences. Thus, it remains unclear as to how many dimensions need to be reported/experienced before flow can be considered to have occurred. This

1sslie is complicated further by suggestions that flow can range from micro (low-intensity) to macro (deep) flow states (e.g., Csikszentmihalyi, 1992).

Summary. Collectively, these critiques suggest that: (i) the flow framework is based on broad, overlapping, and imprecisely defined dimensions with varying levels of support; and (ii) there is a lack of consensus regarding the number and/or combination of dimensions required to classify a flow state. These problems mean that Csikszentmihalyi's conceptualization of what individuals 
experience during flow is somewhat unclear. Furthermore, such issues are often overlooked (e.g., in questionnaires that continue to measure dimensions with low support), which indicates that normal science has been established. Through the following sections, we argue that these issues are accumulating and that flow research in sport and exercise is reaching a 'crisis point' (Kuhn, 1996).

\section{How and When Does Flow Occur?}

There has been extensive research in sport and exercise on the occurrence of flow, particularly from a qualitative perspective (e.g., Jackson, 1995). A systematic review of flow in elite sport (Swann et al., 2012) highlighted 12 facilitators of flow, such as: effective preparation; positive thoughts and emotions; optimal environmental and situational conditions; positive feedback; and optimal motivation and arousal. While these factors may facilitate fiow, it remains that these are simply associations rather than causal mechanisms (Mackie, 1980 Swann, Piggott, Crust, Keegan, \& Hemmings, 2015). For example, effective preparation is simply associated with flow occurrence, but not necessarily involved as a causal mechanism, as fiow may still occur in its absence (Swann et al., 2012). In addition to qualitative work, extensive research on flow using questionnaire-based, correlational designs has further highlighted associations with flow (e.g., goal orientations - Stavrou et al., 2015). Thus, research on flow occurrence to date is primarily based on evidence of constructs associated with flow, rather than causat mechanisms, resulting in recent calls for the need to build towards a causal explanation of flow (Kimiecik \& Stein, 1992; Swann, Crust, \& Vella, 2017). Furthermore, much of this evidence stems from use of questionnaires based explicitly on Csikszentmihalyi's nine dimensions, which poses the issues discussed above.

As noted above, the common conceptualization of flow outlines nine dimensions: six of which are simply proposed to describe characteristics of the experience, with the remaining three d:mensions (challenge-skill balance, clear goals, unambiguous feedback) proposed to be conditions of flow (e.g., Nakamura \& Csikszentmihalyi, 2002). While these necessary conditions are proposed, together they are not sufficient for flow to occur - as evidenced by the issue that flow experiences 
remain rare and elusive despite over 40 years of research. Indeed, this issue was highlighted recently by Csikszentmihalyi et al. (2017):

$[\mathrm{N}] \mathrm{o}$ magic formula exists for creating flow. You cannot conjure it up by following a recipe or rigidly adhering to a series of steps. Although certain conditions must be present for flow to occur, their presence does not guarantee that flow will occur (p.vi).

As such, the sufficient conditions of flow remain unknown, and this fundamental issue raise: questions as to whether current understanding of flow represents a theory.

\section{Is the Conceptualization of Flow a Theory?}

A range of terms have been used in relation to flow. For example, Csikszentmihalyi (1975) originally described flow as a "theoretical model of enjoyment" (pp.35-54), and discussed the "model of flow" (p.49), while later referring to "flow theory" (e.g. Nakamura \& Csikszentmihalyi, 2009). In sport and exercise, researchers refer to the "flow model" (e.g., Koehn et al, 2013) and "flow theory" (e.g., Stavrou et al., 2015). Generally, challenge-skill balance has been considered the primary condition for flow occurrence (see Fons, Zaleski \& Leach, 2015), and a number of models based on challenge-skill balance have esnørgea and evolved since Csikszentmihalyi's (1975) initial work. Models are descriptive in nature, iypically involving a deliberate simplification of a phenomenon or a specific aspect of a phenomenon, and stating relationships among constructs (Moneta, 2012; Nilsen, 2015). These flow models generally postulate how combinations of high and low challenge and skill can lead to cutcones such as boredom, anxiety, and flow (see Moneta, 2012 for a review). While there is support for challenge-skill balance as an important factor in flow (Fong et al., 2015), alone it is in ulficient for these states to occur (as discussed above).

What is a good theory? Although description is an essential first step (Pentland, 1999), explanation is considered to be the core of a good theory, and indeed, without an explanation it can be argued that there $i s$ no theory (Sutton \& Straw, 1995). For example, Sutton and Straw (1995, p.378) suggest that: 
Theory is the answer to queries of why. Theory is about the connections among phenomena, a story about why acts, events, structure, and thoughts occur. Theory emphasizes the nature of causal relationships, identifying what comes first as well as the timing of such events. Strong theory...delves into the underlying processes so as to understand the systematic reasons for a particular occurrence or non-occurrence.

That is, a "good theory provides a clear explanation of how and why specific relationships lead to specific events" (Nilsen, 2015, p.2). Given that flow remains a rare, elusive phenomeron (e.g, , Aherne et al., 2011; Csikszentmihalyi et al., 2017), and the sufficient conditions for its socurrence are presently unknown, it could be argued that the common nine-dimensions cenceptualization of flow is not an explanatory theory. Instead, it may be considered a framework, which describes a phenomenon in terms of its constructs or variables but does not provide an explanation (Nilsen, 2015).

Proximal vs. distal theories. In terms of moving forward in this field, the distinction between proximal and distal theories is also important to consider (see Kanfer, 1990 for a discussion in relation to motivation theory). For exampie, proxinal explanation of a death may be lack of oxygen in the brain; a distal explanation may address the person's involvement in a car crash. Researchers have forwarded neuroscientific explanations of flow based on proximal causes (e.g., transient hypofrontatliy; Dietrich, 2014). Such theories of proximal causation may offer insight beyond that of Csikszentmihalyi's fiamew ork, and may be able to explain aspects of what happens in the brain or body as flow gccurs, however, these proximal theories do not inform coaches/practitioners how to reliably induce flow among athletes and exercisers.

Initaily at least, the most useful explanation of flow would arguably be distal. To explain flow occurrence, this type of explanation would account for: (a) the necessary and sufficient conditions involved; (b) how these conditions interact with each other; and (c) how they interact with, or subsequently produce, the characteristics experienced during flow. With such knowledge, researchers could then more easily, and more robustly, develop proximal explanations of flow (e.g., through more reliable strategies for inducing flow experimentally). Inherently this approach assumes 
a realist philosophy (e.g., Sayer, 2010), similar to Kimiecik and Stein (1992), in assuming that flow has causal mechanisms and can be causally explained through the identification of such mechanisms. Realist philosophy differs from the phenomenological approach Csikszentmihlayi appeared to take in his initial (1975) work and remains aligned with in his later work (see Csikszentmihalyi, 1992). We argue that to make scientific progress (discussed further below) in flow research in sport and exercise, a realist philosophy, with an active interest in causality, is required. In turn, a shift in methodslogy may also be required, for example, towards prospective, longitudinal, and/or 'event-focused' designs (see Methodological Issues: Career-Based vs Event-Focused Perspectives).

\section{Issues in Applying Flow}

Without a strong explanatory theory, there is little causal evidence for coaches or practitioners to reliably draw upon in attempting to use Csikszentmihalyi's $(1975,2002)$ conceptualization to induce flow. For example, in health and medical settings, such an evidence base would need to include efficacy, replicability, effectiveness and scalability studies, and draw upon fully powered randomized controlled trials before translating into pracíce (e.g., Sallis, Owen \& Fotheringham, 2000). It is presently difficult to conduct experimental work on flow due to vague conceptualization of the flow experience/dimensions, issues in measurement, and limited understanding of causal mechanisms, or necessary and' sufficient conditions. As Moller, Meier and Wall (2010 note:

It is infeasible, at the moment, to attach a high-resolution brain scanner...to an athlete's or artist's head and have him or her wander around until an episode of flow sets in... Trying to indree flow in the lab is a bit like trying to make someone relax in a dentist's chair... While it is certainly possible, the task is far from easy, as the cold laboratory context often seems less than conducive, and the flow experience can be elusive, even under seemingly optimal conditions (p.192-193).

As a result, much of the research on flow in sport and exercise, and flow research generally, has used interviews and correlational designs (Engeser \& Schiepe-Tiska, 2012), with comparatively little experimental research on flow in this domain (Swann et al., 2012). In experimental studies to date, 
flow has typically been measured as a secondary outcome (e.g., of various characteristics of music; Karageorghis et al., 2008), with fewer studies that explicitly aimed to induce flow as the dependent variable. Recent exceptions include Harris, Vine and Wilson (2017) who set incrementally more difficult specific goals to induce flow through challenge-skill balance; however similar work (Schweickle et al., 2017) found contradictory evidence that incrementally more difficult specific goals are detrimental to flow, and induce a more effortful state instead. Regardless, there is generally little research in sport and exercise that focuses specifically on experimentally inducirig inow

In turn, it could be argued that intervention studies on flow in sport and exercise are premature. Such intervention studies have typically focused on skills and strategies that are not strongly linked to the occurrence of flow (e.g., hypnosis - Lindsay et al., 2005; mindfulness - Aherne et al., 2011). Intervention research designs have been small, and the resuling evidence has been largely inconclusive (Swann et al., 2012) in comparisen to weli-established, robust theories in psychology such as self-determination theory (Deci \& Ryan, 1985). Fundamentally, there is weak knowledge of the conceptualization and operationatization of flow, which has subsequent effects in terms of inability to conduct stronger (e.g., experimental) research designs, and means that intervention studies are weak or inconclusive. As a result, there is an extremely limited evidence base for coaches and practitioners to confidently apply principles based on flow in applied settings. This issue is perhaps illustrated by the absence of empirical research on flow in sport coaching.

\section{A 'Crisis Point' in Flow Research in Sport and Exercise?}

In addition to the above criticisms and 'anomalies', a number of insights have emerged iecentry which, taken together, suggest that flow research in sport and exercise could be reaching a 'crisis point' (Kuhn, 1996). Emerging evidence and critical questions/problems highlight issues in fundamental assumptions about how to conceptualize and measure flow in this domain. Given these problems, it is difficult to confidently proceed with the traditional paradigm centered on Csikszentmihalyi's conceptualization of flow as nine dimensions. Thus, we suggest that research in 
this field may be moving towards a paradigm shift and a period of 'scientific revolution' or 'extraordinary science' to address the issues.

\section{Does the Flow Conceptualization Conflate Two Distinct Psychological States?}

There is emerging evidence that the nine-dimensions conceptualization, as currently described, conflates (at least ${ }^{3}$ ) two distinct psychological states. This evidence stems from activities including sport (Swann, Crust \& Vella, 2017), leisure (Houge Mackenzie et al., 2011, 2013), and occupational therapy (Wright, Wright, Sadlo \& Stew, 2014). For example, it has bren suggested that there are 'different types of flow', by drawing upon Reversal Theory to propose 'telic flow' and 'paratelic flow' (Houge Mackenzie et al., 2011, 2013; Wright et al., 2014). Alternatively, Swann and colleagues (2016, 2017a, 2017b, 2017c) have reported a second clutch' state, which shares overlapping characteristics with flow, but is distinct (i.e., different to tow, and both cannot be experienced at the same time). Together, this work suggests that Csikszentmihalyi's nine-dimensions conceptualization may conflate two distinct states.

Telic and paratelic flow. In adventure activities, Houge Mackenzie et al (2013, p.218) reported: "a range of flow states that appears d to be related to different metamotivational state phases...[and flow] appeared to have aifferent manifestations (e.g., telic flow and paratelic flow) depending on the phase and context in which it occurred" (p.227). Similar findings have been reported by Wright et a1. in occupational science where:

there night be various psychological states in which a person may be absorbed in an enjoyable occupation to the extent that they lose track of time and forget everything else apart from what they are focusing on at that particular moment (2014, p.183).

\footnotetext{
${ }^{3}$ The evidence presented here suggests that two distinct states are conflated within the nine-dimensions framework. It may be the case that other states, such as psychological momentum, are similarly conflated but without such evidence as yet we refer to two states specifically.
} 
Telic flow (Houge Mackenzie et al., 2011) is proposed to occur in a challenging activity with clear/distinct outcome goals, and is characterized by: an achievement focus; intensity; immersion in the task; seriousness; trying to do what was planned; and having higher performance expectations. In addition, enjoyment is generally reported afterwards rather than during the activity, as a result of successfully completing the task (Houge Mackenzie et al., 2011). Further, attentional narrowing is required to complete the challenging task. Conversely, paratelic flow (Houge Mackenzie et al., 2011) is proposed to be undertaken without a clear outcome goal, and a lack of importance attikuted to performance outcomes and future concerns. It is sensation oriented, exciting, and/or playrul, with a heightened sense of immersion; less intense than telic flow; employs a wider attentional field; and depends less on successful completion of clear tasks, and more on participation in an engaging activity.

Under scrutiny, however, this interpretation of flow using reversal theory could be considered problematic. Flow describes one form of subjective experience - a distinct psychological state which means that the suggestion of two different types of one flow state is not consistent with its definition or conceptual basis. Furthermore, the conceptualization of flow should ideally be parsimonious; that is, one concept should not require explanation by another (e.g., Baker, 2016), as is the case by interpreting flow using reversal theory. Indeed, this process is likely to lead to further definitional and conceptual overlaps rather than scientific progress. Thus, if there is evidence for a similar psycholegical state to flow, then it would arguably be more constructive to define and delineate exactly what low is, and conceptualize separately what the other state is.

Flow and clutch states. Recently, a refined and expanded perspective has emerged that includes a second distinct, yet overlapping, "clutch" state which also underlies excellent performance in sport (Swann et al., 2016, 2017b; see Figure 1). This evidence suggests that Csikszentmihalyi's nine dimensions - and measures based on those dimensions (discussed below) - capture both of these states; that is, the existing conceptualization of flow conflates both flow and clutch states as one (Jackman, Crust \& Swann, 2017). 
Clutch performance has been defined previously as "any performance increment or superior performance that occurs under pressure situations" (Otten, 2009 p. 584). Clutch states differ from flow in a number of ways, whilst also sharing a range of overlapping characteristics. Specifically, clutch states are characterized by complete and deliberate focus on the task, whereas flow is characterized by effortless attention; clutch states involve heightened awareness of the situation and its demands, whereas flow involves positive feedback and feelings that 'everything is going to pian'; and clutch states involve intense effort, in contrast to flow which is characterized by an effortless, automatic experience. Common to both states, however, are the experiences of enjovmient enhanced motivation, perceived control, altered perceptions of time and the environmentit, abserntion, and confidence (Swann et al., 2017a). These findings have been summarized as a 'tentative solution' (i.e., a starting point for further testing and refinement; Popper, 1959) in an Integrated Model of Flow and Clutch States (Swann et al., 2017a), which also described the contuxts processes of occurrence, and outcomes of each state (see Figure 1). To date this work has been primarily qualitative, and - similar to Csikszentmihalyi’s (1975) initial work - emerged tirough inductive analyses.

Summary. There are similarities in the descriptions of 'telic flow' (Houge Mackenzie et al., 2011) and 'clutch' states (Swann et a1, 2017b). Specifically, both states have been described as more intense than typical descript ors of ilow; and occur in situations involving a clear outcome goal in a challenging task whereby enjoyment is primarily gained afterwards upon reflection on the accomplishment. Together, these overlaps suggest that a second psychological state is encompassed or conflated within the original description of flow as nine dimensions (see Table 1).

\section{Methodological Issues in Flow Research in Sport and Exercise}

Career-based vs. event-focused perspectives. Flow has been conceptualized using 'career-

based' interviews that are not specific to certain events, and instead seek athletes' general reflections of flow more broadly throughout their career (see Swann, Keegan, Crust, \& Piggott, 2016). This approach was used in Csikszentmihalyi's (1975) initial interviews on flow, and in Jackson's (1995, 1996) influential studies on flow in sport, which later informed development of the Flow Scales (e.g., 
FSS-2; see following section). As such, flow has been conceptualized from a 'career-based' perspective. Problematically, these interviews are limited by the risk of athletes forgetting details (Yarrow, Campbell, \& Burton, 1970) or presenting a biased recall (Brewer, Van Raalte, Linder, \& Van Raalte, 1991), as they rely on memory of an event that may have occurred months or years in the past. Furthermore, this method's reliance on memory of past experiences alludes to issues of what Neisser (1981) termed episodic versus repisodic memory. Episodic recall "involves the retrieval of particular autobiographical moments, individual episodes of one's life" (p.114). Repisodic memory involves:

a set of repeated experiences, a sequence of related events that the single recollection merely typifies or represents... (One) is not remembering the "gist" of a single episode by itself, but the common characteristics of a whole series of events...xtract (ing) the common themes that remained invariant across...many experiences (p 114).

When stronger methodologies, which capture more recent data about specific flow states, are employed a different picture emerges. Swann et al. (2010, 2017a) and Jackman et al. (2017) have conducted 'event-focused' interviews as seon as possible after a specific performance (on average four days later in these studies), through which the perspective of flow and clutch states emerged. Similarly, Houge Mackerzite et a!. (2011) employed head mounted cameras followed by same-day interviews, and reported the telic and paratelic flow states described above. 'Event-focused' approaches enable note recent, chronological, and detailed recall of the experiences and processes underlying these states (Reis \& Gable, 2000). In turn, this approach suggests that two distinct psychological states are conflated within the common conceptualization of flow. Arguably, the deveiopment of better theory - i.e., theory that dares to specify causal conditions and sequences (Lakatos, 1970; Hassmén et al., 2016) - cannot be developed with career-based interviews as the accounts are not detailed or accurate enough to track the sequence of events and responses leading to flow. Indeed, it may be the case that use of career-based interviews in early work on flow has led to some of the issues that have been evident in this field as described above (e.g., vague definition of dimensions, apparent aggregation of multiple states into the common conceptualization). 
Issues in the Flow State Scale-2. Further to the issues in conceptualization and measurement of flow discussed above, a number of problems are apparent in arguably the primary measure of flow used in sport and exercise - the Flow State Scale-2 (Jackson \& Eklund, 2004). For example, "research has not rigorously examined how one can interpret the scores from the flow scales to know whether the respondents were in the state of flow" (Kawabata \& Evans, 2016, p.268). Specifically, uncertainty over which dimensions are necessary to constitute a flow state (discussed above) creates probiems lor researchers interpreting data from the FSS-2. To illustrate, a person who had lower scores across ali nine dimensions could have the same FSS-2 score as a person who was high on only a fev dimensions. Quantitatively, these experiences would be similar, yet they copid arguably be very different experiences from a qualitative perspective.

There is also little guidance for deciding what score on specific dimensions constitutes flow. Researchers have attempted to identify cut-off values for specific dimensions, but these have been problematic. For example, Kawabata and Evans (2016) propesed item-average scores of challengeskills balance, clear goals, and unambiguous feedback above 3.4 and below 3.3 as criteria to identify individuals experiencing flow and non-flow, respectively. Jackman et al. (2017), however, reported that of 46 performances meeting Kawabate and Evans' (2016) criteria, only 21 were described as flow during subsequent interviews; while Kawabata and Evans' (2016) criteria were met in 84\% of performances in which athletes did not report flow. Thus, it remains unclear as to whether the primary measure of flow can identify participants who experience it, which is a concern given that much of the research in this field is based on the FSS-2.

Furthermore, recent evidence suggests that the FSS-2 does not discriminate between flow and clutch states. With 10 athletes, across 22 performances, Jackman et al. (2017) compared FSS-2 data againist interviews about the same experiences, and found that the FSS-2 captured clutch states as well as flow. Indeed, Jackman et al. (2017) outlined validity concerns relating to each of the nine subscales representing Csikszentmihalyi's dimensions, and concluded that "the majority of FSS-2 items could represent the experience reported during clutch states" (p.119). These findings are perhaps unsurprising given that clutch states have only emerged recently, through interview approaches which 
had not yet been used at the time that the FSS-2 was developed. Regardless, this initial evidence (if supported elsewhere) raises questions over the validity of the FSS-2, and potentially knowledge of flow based on the FSS-2 to date (e.g., whether the data are specific to flow, clutch, or some combination of both states).

Summary. To summarize, the common conceptualization of flow, the primary measure available (FSS-2), and much of the research on flow in sport and exercise to date stems from a 'career-based' perspective. 'Event-focused' studies yield a different picture and raise questions over fundamental assumptions about flow to date. Specifically, recent evidence suggests that Csikszentmihalyi's conceptualization of flow conflates two states into one, and that the primary measure of flow in sport and exercise (FSS-2) may demonstrate low discriminant validity. This emerging evidence raises questions and doubt over fundamenta! assumptions in the conceptualization and measurement of flow in sport and exercise, which stems from initial career-based interviews. Therefore, it can be argued that the field is approashing a crisis point, whereby it is difficult to confidently proceed with the traditional nine-dimensiens yaradigm.

\section{Moving Forward: Ways of Making Scientific Progress}

As explained earlier in this paper the Kuhnian and Popperian views of science come with very different definitions of progress. Where Kuhn associated progress with the extension of the paradigm and inceased rate of puzzle-solving, Popper argued for a realist view where theories become increasingly truth-like through the making of bold predictions and submission to increasingly severe criticism. Pyt another way, for Kuhn progress depends on agreement between members of a paradigm. whereas for Popper progress depends on disagreement and criticism (Popper, 1994). There exists, however, a third view that tries to reconcile these polar positions: that of Popper's student and staccessor, Imre Lakatos.

Like Popper, Lakatos (1970) offered normative ideas for evaluating the state of what he called 'research programs', or a series of theories (akin to a paradigm). Rather than distinguishing rules of demarcation between science and pseudoscience, Lakatos tried to distinguish good science 
from bad (Motterlini, 1999). Siding with Kuhn, Lakatos believed that it was necessary for scientists to defend their research programs with some tenacity, especially in the early stages of development. In line with Popper, however, he also argued that they should not attempt to save research programs from criticism by creating ad-hoc hypotheses (i.e., 'patching up procedures'), as anomalies emerge. Good scientific theories should be made to "stick their necks out" (Lakatos, 1970, p.111) by making bold predictions - ruling out specific states of affairs - and specifying 'rejection rules', or conditions under which criticism of a theory would be accepted. The continuous defense and attack of research programs, Lakatos imagined, would be a "long and often frustrating process" (1070 p. 179), but one that ought to be evaluated against two clear ideal types he called progressive (move tovards) and degenerating (move away from).

Degenerating research programs are those where theories do not predict novel facts and where scientists consistently 'save' theories from criticism with the invention of new ad-hoc hypotheses. Progressive research programs, on the other hand, contain theories that make bold predictions and, as a consequence, are likely to have unàegone and survived harsher criticism than rival theories (Motterlini, 1999). Scientists should therefore prefer to work on, and invest resources in, progressive programs. In cases where no real choice of research program exists (arguably in the case of flow), Lakatos (1970) prcposed that scientists initiate 'progressive shifts' by following 'sophisticated' Popperian principles: (i) developing theories that are more testable, and (ii) submitting them to harsher tests, hus increasing their degree of corroboration, or modifying them through 'error elimination

So far we have argued that the flow paradigm is approaching a moment of 'crisis' (cf. Kuhn, 1996), given the volume of unanswered criticism and 'anomalies' that have emerged. Another, perhaps more constructive, way of putting this is to suggest that flow research is degenerating (e.g., the failure to predict flow; a priori coding of data into existing dimensions; soft correlation-based tests etc.) and is therefore awaiting a progressive shift. Table 2 highlights examples that may characterize progressive and degenerative research at this point. Such a shift would be characterized by the development of theory that attempts to define the necessary and sufficient conditions that cause 
flow to occur (as described above). Such theory would make clear predictions and thus be more amenable to 'testing' and likely increase in corroboration - as is the case with the preliminary Integrated Model of Flow and Clutch States (Swann et al., 2017a). With more testable theory comes harsher tests (e.g., event-focused, stimulated recall interviews and direct observation; experiments; randomized controlled trials; more accurate psychometric instruments) and also more practical applications.

\section{Possibilities for a Practically Useful Theory in Sport and Exercise}

A progressive shift of the sort mentioned above - with the development of a distal causal explanation outlining necessary and sufficient conditions - should also be practically useful. Currently it is difficult, if not impossible, for coaches and athletes to reliably induce flow based on Csikszentmihlayi's conceptualization. With the explanation of mechanisms underlying the occurrence of flow (and overlapping states, like clutch), athletes, coaches, and sport science practitioners may be better able to create interventions and practices to incuce and manage (e.g., prolong) them. Furthermore, reliable manipulation of flow experiences would enable stronger research designs that can provide more robust evidence on the causal relationships between flow and outcomes such as performance, wellbeing, and mot vation. $\mathrm{h}$ would also enable the systematic investigation of psychological and behavioral strategies that can be used to induce and/or maintain the flow state. For example, a practically iseful theory should inform athletes and exercisers of strategies for inducing and maintaining such states, and how/when to use them. Another primary consideration for coaches, practitioners and atnletes/exercisers is understanding "when is the right time to be in flow?" For exarnple, clutch states appear to be more constructive during pressure phases when an outcome is on the line; whereas flow states appear to be useful in contexts of exploration, discovery, and experimentation (Swann et al., 2017a). Therefore, a practically useful theory should include knowledge of the type of context necessary to experience flow (e.g., across stages of a season; within phases of a specific performance). By informing coaches and practitioners of the right time or context to experience flow, and how to get there, a practically useful theory could assist in decision-making regarding when (e.g., half time; calling time outs), and how to communicate with athletes 
experiencing flow. A strong, practically useful theory could therefore be relevant from grassroots to elite sport, and from beginners to experienced exercisers.

\section{Conclusion}

Csikszentmihalyi's concept of flow has generated extensive interest in sport and exercise. Important work has been done to conceptualize flow experiences (e.g., Csikszentmihalyi, 1975; Jackson, 1996), and lay a foundation for research in this domain. We argue that a period of norma! science' (Kuhn, 1996) has ensued, and that a series of criticisms or 'anomalies' have gradually accumulated in this field, which have been accelerated by recent insights stemming fron an 'eventfocused' perspective (e.g., Swann et al., 2016). In turn, we argue that the rieid is reaching a 'crisis point' in terms of apparent flaws in the existing conceptualization and common measures of flow (e.g., the FSS-2), which seem to conflate multiple psychological states as one. If this argument is accepted, questions could be raised over much of the knowledge of flow generated to date (e.g., regarding the experience, occurrence, and factors associated with the nine-dimensions conceptualization). We argue that these probleris and questions can be addressed with the adoption of 'progressive' (i.e. Popperian or Lakatosian) attituades and methods that aim to criticize existing knowledge of flow and foster more testable heories concerning flow occurrence. The development of a more progressive research prog am will also likely lead to more useful theories that will better inform coaches, practitioners, athletes, and exercisers seeking flow states.

In The Structure of Scientific Revolutions, Kuhn imagined that periods of normal science and revolytionary science occurred in a strict sequence and could not overlap. Kuhn's critics, however (netably Lakatos and Feyerabend - see Motterlini, 1999), argued that communities of researchers may contain two kinds of scientist - 'defenders' and 'attackers' of the paradigm, who exist and interact simultaneously. Indeed, a critical interaction between these two is arguably necessary for scientific progress to occur (Lakatos, 1970). Thus, we seek to stimulate critical discussion around the state of flow research in sport and exercise, with the ultimate aim of making scientific progress through improved understanding and application of this highly desirable phenomenon. 


\section{References}

Aherne, C., Moran, A. P., \& Lonsdale, C. (2011). The effect of mindfulness training on athletes' flow: An initial investigation. The Sport Psychologist, 25(2), 177-189.

Baker, A. (2016). Simplicity. In E. Zalta (Ed.), The Stanford Encyclopedia of Philosophy, https://plato.stanford.edu/archives/win2016/entries/simplicity/

Bernier, M., Thienot, E., Codron, R., \& Fournier, J. (2009). Mindfulness and acceptance âpprøaches in sport performance. Journal of Clinical Sports Psychology, 4, 320-333.

Brewer, B. W., Van Raalte, J. L., Linder, D. E., \& Van Raalte, N. S. (1991). Feak performance and the perils of retrospective introspection. Journal of Sport and Exercise Psychology, 13(3), 227238.

Chavez, E. J. (2008). Flow in sport: A study of college ahletes Imagination, Cognition and Personality, 28(1), 69-91.

Csikszentmihayli, M. (1975). Beyond boredom ana anxiety: Experiencing flow in work and play. San Francisco, California: Jossey-Bass.

Csikszentmihalyi, M. (1978, Intrinsic rewards and emergent motivation. In M. Lepper and D. Greene (Eds.), The hidden cests of reward: New perspectives on the psychology of human motivation (pp. 205-216). New Jersey: Lawrence Erlbaum Associates.

Csikszentmihalyi.1M. (1988). Introduction. In M. Csikszentmihalyi \& I. S. Csikszentmihalyi (Eds.), Cptimal experience: Psychological studies of flow in consciousness (pp. 3-14). New York, NY: Cambridge University Press.

Csikszentmihalyi, M. (1990). Flow: the psychology of optimal experience. New York: Harper \& Row.

Csikszentmihalyi, M. (1992). A response to the Kimiecik \& Stein and Jackson papers. Journal of Applied Sport Psychology, 4, 181-183. 
Csikszentmihalyi, M. (2000). Beyond boredom and anxiety: The $25^{\text {th }}$ anniversary edition. San Francisco: Jossey-Bass.

Csikszentmihalyi, M. (2002). Flow: the psychology of optimal experience (2nd Ed.). New York: Harper \& Row.

Csikszentmihalyi. M., Latter, P., \& Weinkauff Duranso, C. (2017). Running flow. Champaign, 1: Human Kinetics.

Deci, E. L., \& Ryan, R. M. (1985). Intrinsic motivation and self-determination in haman behaviour. New York, NY: Kluwer.

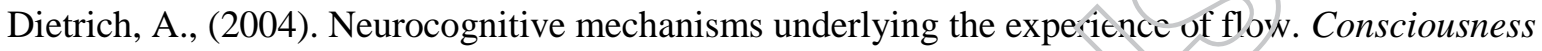
and Cognition, 13, 746-761.

Engeser, S. (2012). Comments on Schiefele and Raabe (201 1): 1low is a multifaceted experience defined by several components. Psychologicai Reports 111, 24-26.

Engeser, S., \& Rheinberg, F. (2008). Flow, performance, and moderators of challenge-skill balance. Motivation and Emotion, 32, 15\%-172.

Engeser, S. \& Schiepe-Tiska, A. (21) Listorical lines and overview of current research in flow. In S. Engeser (Ed.), Advances in fiow research (pp.1-22). New York: Springer

Fuller, S. (2005). The philosophy of science and technology studies. London: Routledge.

Hardy, L., Jones, G., \& Gould, D. (1996). Understanding psychological preparation for sport. Chichester, UK: John Wiley \& Sons.

Harnison, R. J. (2011). Peak performance in sport: Identifying ideal performance states and developing athletes' psychological skills. Sport, Exercise, and Performance Psychology, 1(S), 318.

Harris, D., Vine, S., \& Wilson, M. (2017). Flow and quiet eye: the role of attentional control in flow experience. Cognitive Processing, doi: 10.1007/s10339-017-0794-9. 
Hassmén, P., Keegan, R., \& Piggott, D. (2016). Rethinking sport and exercise psychology research. London, UK: Springer Nature.

Hodge, K., Lonsdale, C., \& Jackson, S. A. (2009). Athlete engagement in elite sport: An exploratory investigation of antecedents and consequences. The Sport Psychologist, 23, 186-202.

Hoffman, D.L, \& Novak, T.P. (2009). Flow online: Lessons learned and future prospects. Jourhal of Interactive Marketing, 23, 23-34.

Houge Mackenzie, S., Hodge, K., \& Boyes, M. (2011). Expanding the flow model in advent-are activities: A Reversal Theory perspective. Journal of Leisure Research, 43, 519-544.

Houge Mackenzie, S., Hodge, K., \& Boyes, M. (2013). The multiphasic and dynamic nature of flow in adventure experiences. Journal of Leisure Research, 45, 214-232.

Jackman, P. C., Crust, L., \& Swann, C. (2017). Systematically cornparing methods used to study flow in sport: A longitudinal multiple-case study. Psychold gy of Sport \& Exercise, 32, 113-123.

Jackman, P., Fitzpatrick, G., Lane, A., \& Swann, C. (2017). Exploring bodily sensations experienced during flow states in professional national hunt jockeys: a connecting analysis. Qualitative Research in Sport, Exercise and Healih, doi: http://dx.doi.org/10.1080/2159676X.2017.1380693

Jackson, S., (1992). Athietes in 19w: A qualitative investigation of flow states in elite figure skaters. Journal of Applied Sport Pyychology, 4, 161-180.

Jackson, S., (1995). Factors influencing the occurrence of flow state in elite athletes. Journal of Applied Sport Psychology, 7, 138-166.

Jackson, S., (1996). Toward a conceptual understanding of the flow experience in elite athletes. Research Quarterly for Exercise and Sport, 67(1), 76-90.

Jackson, S., \& Csikszentmihalyi, M. (1999). Flow in sports: The keys to optimal experience and performances. Champaign, IL: Human Kinetics.

Jackson, S., \& Eklund, R. (2002). Assessing flow in physical activity: The Flow State Scale-2 and 
Dispositional Flow Scale-2. Journal of Sport \& Exercise Psychology, 24(2), 133-150.

Jackson, S., \& Eklund, R. (2004). The flow scales manual. Morganstown, WV: Fitness Information Technology.

Jackson, S., \& Kimiecik, J. (2008). Optimal experience in sport and exercise. In T.Horn (ed.), Advances in sport psychology (3rd edition, pp.377-399). Champaign, IL: Human Kinetics.

Jackson, S., \& Marsh, H. (1996). Development and validation of a scale to measure optima! experience: The Flow State Scale. Journal of Sport and Exercise Psychology, 18, 17-35.

Jackson, S., \& Roberts, G. C. (1992). Positive performance states of athletes: Tovvard a conceptual understanding of peak performance. The Sport Psychologist, 6(2, $156-171$.

Jackson, S., Thomas, P., Marsh, H., \& Smethurst, C. (2001). Relationships between flow, selfconcept, psychological skills, and performance. Journal of Appiied Sport Psychology, 13, 129153.

Kanfer, R. (1990). Motivation theory and industrial/organizational psychology. In M.D. Dunnette and L. Hough (Eds.), Handbook of industrial and organizational psychology. Volume 1. Theory in industrial and organizationat psychology (pp. 75-170). Palo Alto, CA: Consulting Psychologists Press.

Karageorghis, C, Jones. L., \& Stuart, D. (2008). Psychological effects of music tempi during exercise Incernational Journal of Sports Medicine, 29, 613-619.

Kimiecik, J \&r Stein, G. (1992). Examining flow experiences in sport contexts: conceptual issues and methuciological concerns. Journal of Applied Sport Psychology, 4, 144 - 60.

Koehn, S., Morris. T., \& Watt, A. (2013). Flow state in self-paced and externally-paced performance contexts: an examination of the flow model. Psychology of Sport and Exercise, 14, 787-795.

Kowal, J., \& Fortier, M. S. (1999). Motivational determinants of flow: Contributions from SelfDetermination Theory. The Journal of Social Psychology, 139(3), 355-368. 
Kuhn. T. (1996). The structure of scientific revolutions (3rd ed.). Chicago: University of Chicago Press.

Lakatos, I. (1970). Falsification and the methodology of scientific research programmes. In I. Lakatos and A. Musgrave (Eds.), Criticism and the growth of knowledge. New York: Cambridge University Press.

Lindsay, P., Maynard, I., \& Thomas, O. (2005). Effects of hypnosis on flow states and cycling performance. The Sport Psychologist, 19, 164-177.

Locke, E. A., \& Latham, G. P. (2013). New developments in goal setting and task performance. New York, NY: Routledge.

Mackie, J. (1980). The cement of the universe: A study of causation. Oxford: Oxford University Press.

Magee, B. (1973). Karl Popper. New York: Viking Press.

Moller, A.C., Meier, B.P., \& Wall, R.D. (2010) Develering an experimental induction of flow: Effortless action in the lab. In B. Bruya (Ed), Effortless attention: A new perspective in the cognitive science of attention ana action (pp.191-204). Cambridge, MA: MIT Press.

Moneta, G. (2012). On the measurement and conceptualization of flow. In S. Engeser (Ed.), Advances in flow research (pp.23-50). Sy itzerland: Springer.

Moran, A. \& Toner, J. (2017). A critical introduction to sport psychology. London: Taylor \& Francis.

Motterlini M. (1999). For and against method: including Lakatos's lectures on scientific method and the Lal:atos-Feyerabend correspondence. Chicago, Il: University of Chicago

Nakanura, J., \& Csikszentmihalyi, M. (2002). The concept of flow. In C.R. Snyder \& S.J. Lopez (Eds.), Handbook of positive psychology (pp.89-105). New York: Oxford University Press.

Nakamura, J., \& Csikszentmihalyi, M. (2009). Flow theory and research. In C.R. Snyder \& S.J. Lopez (Eds.), Oxford handbook of positive psychology ( $2^{\text {nd }}$ Ed.; pp. 195-206). New York: Oxford University Press. 
Neisser, U. (1981). John Dean's memory: A case study. Cognition, 9, 1-22.

Nilsen, P. (2015). Making sense of implementation theories, models and frameworks. Implementation Science, 10, 1-13.

Otten, M. (2009). Choking vs. clutch performance: a study of sport performance under pressure. Journal of Sport \& Exercise Psychology, 31(5), 583-601.

Pentland, B.T. (1999). Building process theory with narrative: From description to explanation. Academy of Management Review, 24, 711-724.

Pires, F. (2013). Thomas Kuhn's 'Structure of Scientific Revolutions' applied to exercise science paradigm shifts: example including the Central Governor Model. British Journal of Sports Medicine, 47, 721-722

Popper, K. (1959). The logic of scientific discovery. London: Hutchinson \& Co.

Popper, K. (1970). Normal science and its danzers. In I. I akatos and A. Musgrave (Eds.), Criticism and the growth of knowledge (pp. 51-58). Cambridge, UK: Cambridge University Press.

Popper, K.R. (1981). The rationality of scientific revolutions. In I. Hacking (Ed.) Scientific Revolutions. Oxford: Oxiord Uiniy ersity Press.

Popper, K. (1994). The myth of the framework: In defence of science and rationality. London: Routledge.

Reis, H. T, \& Gable, S. L. (2000). Event-Sampling and Other Methods for Studying Everyday Experience. In Handbook of research methods in social and personality psychology (pp. 19022.2). Cambridge, UK: Cambridge University Press.

Rulodes, R., \& Kates, A. (2015). Can the affective response to exercise predict future motives and physical activity behavior? A systematic review of published evidence. Annals of Behavioural Medicine, 49, 715-731. 
Robergs, R. A. (2017). Lessons from Popper for science, paradigm shifts, scientific revolutions and exercise physiology. BMJ Open Sport \& Exercise Medicine, 3(1), e000226.

Rowbottom, D. P. (2011). Kuhn vs. Popper on criticism and dogmatism in science: a resolution at the group level. Studies in History and Philosophy of Science, 42(1), 117-124.

Sallis, J., Owen, N. \& Fotheringham, M. (2000). Behavioral epidemiology: A systematic framework to classify phases of research on health promotion and disease prevention. Annals of Beriavioral Medicine, 22, 294-298.

Sayer, A. (2010). Method in social science: A realist approach (Revised 2/ edition). London: Routledge.

Schiefele, U. (2013). Response to Engeser (2012): On the nature or the flow experience. Psychological Reports: Mental \& Physical Health, 112, 529-532.

Schüler, J., Brandstätter, V., \& Sheldon, K. (2013). De irnplicit motives and basic psychological needs interact to predict well-being and ${ }_{1}$ low? Testing a universal hypothesis and a matching hypothesis. Motivation and Enlotion, 37, 480-495.

Schweickle, M., Groves, S., Vella, S. A., \& Swann, C. (2017). The effects of open vs. specific goals on flow and cluteh tates in a cognitive task. Psychology of Sport \& Exercise, 33, 45-54.

Stavrou, N. A., Psychountaki, M., Georgiadis, E., Karteroliotis, K., \& Zervas, Y. (2015). Flow theory-goal orientation theory: positive experience is related to athlete's goal orientation. Frontiers in Psychology, 6, 1499.

Sugiyama, T., \& Inomata, K. (2005). Qualitative examination of flow experience among top Japanese athletes. Perceptual and Motor Skills, 100, 969-982.

Sutton, R. I., \& Straw, B. M. (1995). What theory is not. Administrative Science Quarterly, 40, 371384.

Swann, C., Crust, L., Jackman, P., Vella, S. A., Allen, M. S., \& Keegan, R. (2017a). Psychological 
states underlying excellent performance in sport: Toward an integrated model of flow and clutch states. Journal of Applied Sport Psychology, 29(4), 375-401.

Swann, C., Crust, L., Jackman, P., Vella, S., Allen, M., \& Keegan, R. (2017b). Performing under pressure: Exploring the psychological state underlying clutch performance in sport. Journal of Sports Sciences, 35, 2272-2280.

Swann, C., Crust, L., \& Vella, S. (2017). New directions in the psychology of optimal performance in sport: flow and clutch states. Current Opinion in Psychology, 16, 48-53.

Swann, C., Keegan, R., Crust, L., \& Piggott, D. (2016). Psychological states uncerlying excellent performance in professional golfers: "Letting it happen" vs. "making it happen." Psychology of Sport and Exercise, 23, 101-113.

Swann, C., Keegan, R. J., Piggott, D., \& Crust, L. (2012). A systernatic review of the experience, occurrence, and controllability of flow states in elite sport Psychology of Sport and Exercise, 13(6), 807-819.

Swann, C., Piggott, D., Crust, L., Keegan, R., \& Hemmings, B. (2015). Exploring the interactions underlying flow states: A connecting analysis of flow occurrence in European Tour golfers. Psychology of Sport and Exer cise, 16, 60-69.

Valenzuela, R., Codina, N., \& Pestana, J. (2017). Self-determination theory applied to flow in conservatoire music practice: The roles of perceived autonomy and competence, and autonomous and controlled moivation. Psychology of Music, 46, 33-48.

Vuelk1, J.E., \& Ellis, G.D. (1998). Measuring flow experiences in daily life: An examination of the items used to measure challenge and skill. Journal of Leisure Research, 30, 380-389.

Wright, J., Wright, S., Sadlow, G. \& Stew, G. (2014). Exploring optimal experiences: A Reversal Theory perspective of flow and occupational science. Journal of Occupational Science, 21, 173187. 
Wrigley, J. \& Emmerson, S. (2013). The experience of the flow state in live music performance.

Psychology of Music, 41, 292-305.

Yarrow, M. R., Campbell, J. D., \& Burton, R. V. (1970). Recollections of childhood: A study of the retrospective method. Monographs of the Society for Research in Child Development, 35(5), iii.

Table 1 Qualitative evidence meeting definitions for Csikszentmihalyi's nine dimensions from both

flow and clutch states

\begin{tabular}{|c|c|c|}
\hline Dimension & Flow & Cluten \\
\hline $\begin{array}{l}\text { Challenge-skill } \\
\text { balance }\end{array}$ & $\begin{array}{l}\text { I really wanted to try and ... test yourself } \\
\text { [sic] in a way, you know, challenge } \\
\text { yourself to do it in the most pressure- } \\
\text { packed situation (1) }\end{array}$ & $\begin{array}{l}\text { I only had three boles ieft of the tournament to } \\
\text { play ... the three [most? important holes ... This } \\
\text { was it, this was ny time now. This is where I } \\
\text { can win (1) }\end{array}$ \\
\hline Clear goals & $\begin{array}{l}\text { I'm at the top [of the leader board]; all I'm } \\
\text { thinking about is ... trying to go forward, } \\
\text { trying to get further in front ... It's the kin } \\
\text { of one-sighted vision that I had to go } \\
\text { further ahead (1) }\end{array}$ & $\begin{array}{l}\text { There's oniy two shots between me and the next } \\
\text { guiv, so now there's a goal there, to finish with } \\
\text { two pars ... There was like a target at the end } \\
\text { that you had to produce (1) }\end{array}$ \\
\hline $\begin{array}{l}\text { Unambiguous } \\
\text { feedback }\end{array}$ & $\begin{array}{l}\text { "nothing can go wrong ... you reei things } \\
\text { going your way" (1); "everything seems to } \\
\text { fall into place" (1) }\end{array}$ & $\begin{array}{l}\text { I was getting into position and getting on } \\
\text { possessions, reading the play well (4) }\end{array}$ \\
\hline $\begin{array}{l}\text { Concentration } \\
\text { on the task at } \\
\text { hand }\end{array}$ & $\begin{array}{l}\text { I think it's just something that happens } \\
\text { naturally ... I'm concentrating...that's for } \\
\text { sure...but it's just sornet'ning that seems to } \\
\text { happen (1) }\end{array}$ & $\begin{array}{l}\text { I made myself focus even more on that last hole } \\
\text {... I was trying a little bit harder to be intense } \\
\text { (1) }\end{array}$ \\
\hline & $\begin{array}{l}\text { [1] wast trying to take one shot at a } \\
\text { time . the same routine for every single } \\
\text { shot. I've come off the } 18 \text { th, looked at my } \\
\text { caddy and said "what score have I shot?" } \\
\text { Because I didn't know (1) }\end{array}$ & $\begin{array}{l}\text { It just feels like I'm so focused and nothing else } \\
\text { is around me ... it's just me and the ball ... that's } \\
\text { it, I don't think about anything else ... nothing } \\
\text { else was happening as far as I was concerned } \\
\text { (1) }\end{array}$ \\
\hline $\begin{array}{l}\text { Sense of } \\
\text { contrsi }\end{array}$ & $\begin{array}{l}\text { It was just controlled all the way } \\
\text { through...I've never experienced that } \\
\text { before... everything was really controlled. } \\
\text { And people said that...I looked quite in } \\
\text { control (2) }\end{array}$ & $\begin{array}{l}\text { when you're fully ... aware of what the situation } \\
\text { was... [and being in] control of the situation (1); } \\
\text { I just felt in control of everything ... it felt like I } \\
\text { had complete control of myself and my } \\
\text { emotions (1) }\end{array}$ \\
\hline $\begin{array}{l}\text { Loss of self- } \\
\text { consciousness }\end{array}$ & $\begin{array}{l}\text { I didn't have any negative thoughts - } \\
\text { everything I saw was positive } 1 \text {; I didn't } \\
\text { care about anything other than making the } \\
\text { right decision (4) }\end{array}$ & $\begin{array}{l}\text { [In] the World Cup Final... with one minute to } \\
\text { go, and everything riding on it...24 years of } \\
\text { history...There's a fair bit of pressure on this...I } \\
\text { wasn't thinking about that. I knew the job I had } \\
\text { to do; I wasn't thinking about } 24 \text { years or what } \\
\text { the crowd thought...I was in a zone. I was }\end{array}$ \\
\hline
\end{tabular}


getting the job done that I've always done and it didn't matter that it was the World Cup final (3)

\begin{tabular}{|c|c|c|}
\hline $\begin{array}{l}\text { Transformation } \\
\text { of time }\end{array}$ & $\begin{array}{l}\text { Time went by quickly (1); I was totally } \\
\text { engaged in the run. It was very rare that I } \\
\text { would have looked at my watch (4) }\end{array}$ & $\begin{array}{l}\text { Looking back on it yeah it did go pretty quick } \\
\text { (1); I'm not thinking of my time. I'm thinking, } \\
\text { "hit that end line: (4) }\end{array}$ \\
\hline $\begin{array}{l}\text { Autotelic } \\
\text { experience }\end{array}$ & $\begin{array}{l}\text { I don't know if I'd have thought at the time } \\
\text { "oh this is really fun". I was just thinking } \\
\text { "this is good". But that's an enjoyable } \\
\text { experience knowing that you're doing well } \\
\text { and thinking that this is going well, so yes, } \\
\text { it was definitely an enjoyable experience } \\
\text { (2) }\end{array}$ & $\begin{array}{l}\text { It's funny because you do enjoy it and you } \\
\text { don't enjoy it. Obviously you want to win, so } \\
\text { with the fact you might lose, you're not } \\
\text { enjoying it in that sense. But you're enjoying } \\
\text { the fact that it's becoming close and, if you end } \\
\text { up winning the set, then the emstion that you'll } \\
\text { feel will be awesome (3) }\end{array}$ \\
\hline
\end{tabular}

Note: 1 = Swann et al. (2016); 2 = Swann et al. (2017a); 3 = Swann et al (2017b); 4 = Jackman et al. (2017)

Table 2 Examples of progressive and degenerative research in current stave of flow in sport and exercise

\begin{tabular}{|c|c|c|}
\hline Classification & Research examples & anation of classification \\
\hline & $\begin{array}{l}\text { Career-based interview studies } \\
\text { seeking to understand } \\
\text { experience and/or occurrence } \\
\text { of flow }\end{array}$ & $\begin{array}{l}\text { Relies on recall of events up to months or years in } \\
\text { the past, resulting in broad/imprecise description of } \\
\text { experiences (e.g., through repisodic memory) which } \\
\text { appear to conflate flow and clutch states, and } \\
\text { identify associations rather than causal mechanisms }\end{array}$ \\
\hline & $\begin{array}{l}\text { Uncritical adoptior of } \\
\text { Csikszentmihalyı's nine } \\
\text { dimersions (e.g., coding } \\
\text { dualitative data into } \\
\text { dimensions a priori, or } \\
\text { development of new measures } \\
\text { based on nine dimensions) }\end{array}$ & $\begin{array}{l}\text { Evidence that nine dimensions conflates two } \\
\text { distinct psychological states, stemming from career- } \\
\text { based foundations; broad and imprecise definition } \\
\text { of nine dimensions, with overlapping } \\
\text { conceptualisation of core aspects of the experience, } \\
\text { and other prominent features of the flow experience } \\
\text { unaccounted for }\end{array}$ \\
\hline & $\begin{array}{l}\text { Uncritical use of FSS-2 (e.g., } \\
\text { to examine correlations with } \\
\text { flow, or to assess flow as a } \\
\text { primary or secondary outcome) }\end{array}$ & $\begin{array}{l}\text { Questions over validity of FSS- } 2 \text { with potential that } \\
\text { it captures both flow and clutch states; issues in } \\
\text { interpreting FSS- } 2 \text { data in terms of cut-offs and } \\
\text { necessary/sufficient dimensions for flow, as well as } \\
\text { low support for some dimensions }\end{array}$ \\
\hline $\begin{array}{l}\text { Progressive } \\
\text { research }\end{array}$ & $\begin{array}{l}\text { Event-focused interview } \\
\text { studies exploring the } \\
\text { experience and/or occurrence } \\
\text { of flow, which minimise the } \\
\text { delay between event and }\end{array}$ & $\begin{array}{l}\text { Enables more recent and detailed recall of specific } \\
\text { experiences (e.g., through episodic memory) where } \\
\text { participants can distinguish between flow other } \\
\text { states (e.g., clutch); chronological recall enables } \\
\text { exploration of chronological sequence of flow }\end{array}$ \\
\hline
\end{tabular}


interview (e.g., conducted occurrence and possible causal mechanisms within hours/days)

Studies seeking to collect real- Allow examination of flow experience during time/in-the-moment data on activities rather than recall after completion of the flow during sport and exercise event; compare in-the-moment data with recall (e.g., event-focused interviews) and potentially refine understanding and conceptualization of the flow experience

Critically examining the validity of FSS-2 and other common measures (e.g., Flow Short Scale; Engeser \& Rheinberg, 2008)
Further test initial evidence that the conceptualization of flow, and the FS $5-2$, confiates flow and clutch states; better understand potential need to re-examine knowledge of niow sternming from these measures (e.g., correlates of flow identified in studies usirg $\Gamma S S-2$ ) 


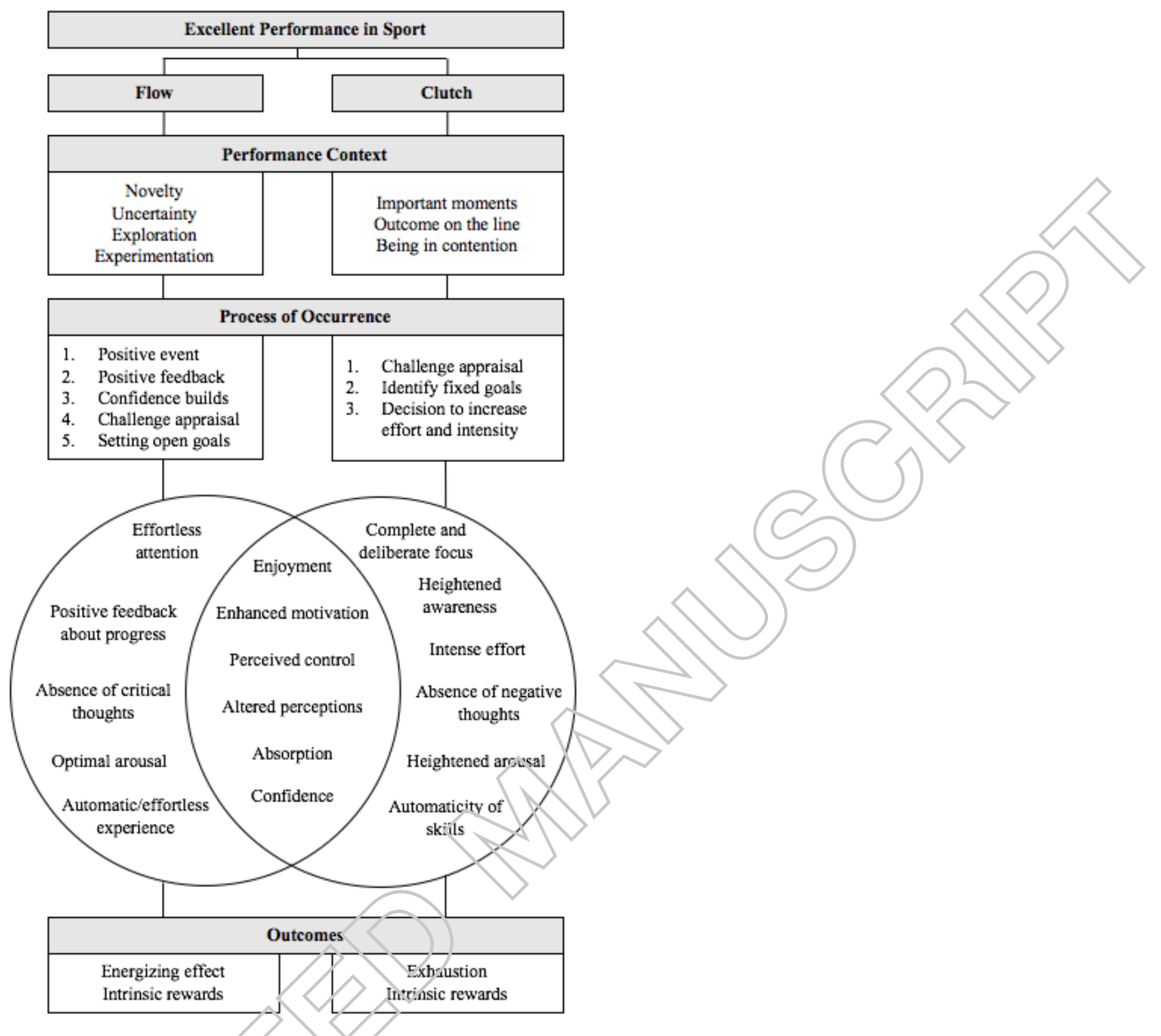

Figure 1: The integrated model of flow and clutch states

Note: Figure as griginally published in Swann, Crust, Jackman, Vella, Allen \& Keegan (2017). Psychological states underlying excellent performance in sport: Towards an integrated model of flow and ciutch states. Journal of Applied Sport Psychology, 29, 375-401. 